\title{
Influence of boehmite intermediate layer as covalent linker on synthesis of LTA zeolite coatings
}

Influencia de la bohemite como enlazador covalente en la síntesis de recubrimientos de Zeolita LTA

\section{Leidys Marleyn Rodríguez-Castro (iD) ${ }^{1 *}$, Miguel Urbiztondo-Castro (iD ${ }^{2}$, Maria Pilar Pina-Iritia (iD ${ }^{3}$}

${ }^{1}$ Facultad de Ciencias Naturales e Ingeniería, Unidades Tecnológicas de Santander. Carrera 28 \# 28-68. C. P. 687031. Barrancabermeja, Colombia.

${ }^{2}$ Ingeniería Ambiental, Centro Universitario de la Defensa (CUD). Carr. de Huesca, s/n. C. P. 50090. Zaragoza, España.

${ }^{3}$ Departmento de Química e Ingeniería Ambiental, Instituto de Nanociencia de Aragon, Universidad de Zaragoza. Campus

Río Ebro, Edif. I+D, C/ Mariano Esquillor Gómez, s/n. C. P. 50018. Zaragoza, España.

\section{CITE THIS ARTICLE AS:}

L. M. Rodríguez, M. Urbiztondo and M. P. Pina. "Influence of boehmite intermediate layer as covalent linker on synthesis of LTA zeolite coatings", Revista Facultad de Ingeniería Universidad de Antioquia, no. 101, pp. 64-73, Oct-Dec 2021. [Online]. Available: https: //www.doi.org/10.17533/ udea.redin. 20200693

\section{ARTICLE INFO:}

Received: February 24, 2020 Accepted: June 25, 2020

Available online: June 25, 2020

\section{KEYWORDS:}

Coating; zeolite; hydrothermal synthesis; boehmite; silicon support

Recubrimiento; zeolita; síntesis hidrotermal; bohemita, soportes de silicio
ABSTRACT: The incorporation of nanostructured materials, such as LTA-type zeolite on the silicon wafers, opens a very interesting door to the use of these materials within silicon based microfabrication technologies. This work studies the deposition and intergrowth of defect-free LTA-type zeolite layer onto 3-inch Silicon wafers with a layer of $\mathrm{SiO}_{2}$ subjected to pretreatment. The main disadvantage associated with zeolite layer synthesis are crack the formation of cracks and difficulty of obtaining a uniform layer. By modifying the supports with boehmite, a substantial improvement was observed in terms of layer continuity and crystal intergrowth in comparrison to coatings prepared on cationic polymer, poly (diallyldimethylammonium chloride). An LTA- type zeolite layer was synthesized in a range of 350 to $1300 \mathrm{~nm}$ via hydrothermal ex-situ method at 363 $\mathrm{K}$ for $12 \mathrm{~h}$. Tetramethylammonium hydroxide (TMAOH) was used as a template, and aluminum isopropoxide and colloidal silica were used as Al and Si sources, respectively.

RESUMEN: La incorporación de materiales nanoestructurados como la zeolita tipo LTA en las obleas de silicio, abre una puerta muy interesante para el uso de estos materiales dentro de las tecnologías de microfabricación basadas en silicio. En este trabajo, se estudió la deposición y el entrecruzamiento de la capa de zeolita tipo LTA libre de defectos en obleas de silicio de 3 pulgadas con una capa de $\mathrm{SiO}_{2}$ sometida a pretratamiento. La principal desventaja asociada con la síntesis de la capa de zeolita es la formación de grietas y la obtención de una capa uniforme. Al modificar los soportes con boehmita, se observó una mejora sustancial en términos de continuidad de capa y crecimiento de cristales en comparación con los recubrimientos preparados en polímero catiónico, poli (cloruro de dialildimetilamonio). Se sintetizó una capa de zeolita de tipo LTA entre un rango de 350 y $1300 \mathrm{~nm}$ mediante un método hidrotermal ex situ, a $363 \mathrm{~K}$ durante $12 \mathrm{~h}$. Se usó hidróxido de tetrametilamonio (TMAOH) como molde y se usaron isopropóxido de aluminio y sílice coloidal como fuentes de Al y Si, respectivamente.

\section{Introduction}

Zeolite is a microporous crystalline aluminosilicate characterized by a three-dimensional framework structure. Connections of $\mathrm{TO}_{4}$ tetrahedral $(\mathrm{T}=\mathrm{Si}$, Al) and neighboring oxygen atoms build up a system of channels and cavities which provide the permeation of

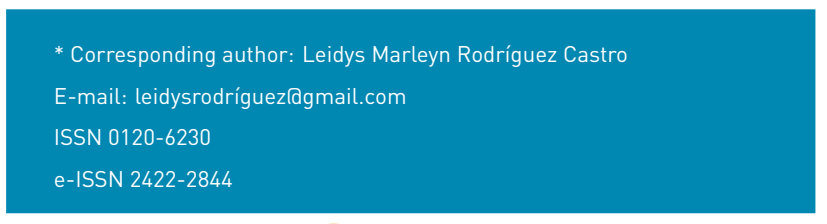

several molecules. When a zeolite framework contains an equal number of aluminum and silicon atoms, molar ratio equals 1 , each oxygen atom is linked to one aluminum and one silicon atom; therefore, the cavities contain the maximum density of exchangeable cations resulting in a high adsorption capacity [1, 2]. At some places of the framework, Silicon $\left(\mathrm{Si}^{4+}\right)$ by aluminum $\left(\mathrm{Al}^{3+}\right)$ replacement provides a charge unbalance. Cations within the structure cavities balance this charge achieving the electroneutrality of zeolite [3]. 
In general, three main properties of zeolites are technologically important: their selectivity and ability as a strong adsorbent and their catalytic activity. All these properties give them a versatile potential for various applications such as gas separation, membrane reactors, chemical sensors, etc. [4-6].

Their incorporation in the production of microdevices has been the focus of recent research: many microdevices have been developed employing zeolites as host materials $[7,8]$ such as interdigital structures, cantilever-based mass sensors [9], micromembranes [4] and microsensors [10]. The applications of this functional material for microdevices fabrications are based on morphology, quality, size and orientation of crystal zeolite.

Zeolite film synthesis involves the hydrothermal crystallization of active hydrated aluminosilicate gels or sols onto porous support in a basic environment. The gel is defined as an aqueous solution containing a silica source, an aluminum source and an alkali source. During the hydrothermal synthesis, often developed at high temperature and high pressure ( $>100^{\circ} \mathrm{C},>1$ bar), the crystallization is influenced by well-known factors such as reactant sources, Si/Al ratio, alkalinity, water content, inorganic cations, organic templates, solvents, temperature, aging, stirring, and seeding. This process could take from a few hours to several days [11].

The hydrothermal synthesis procedure can be ex situ and in situ, with and without a previous seeding step, respectively. The in situ hydrothermal synthesis is carried out by immersing the support into the synthesis solution; the layer is formed by direct crystallization. Coating the zeolite seed on the support surface lex-situ method) accelerates the zeolite crystallization process and enhances the formation of homogeneous layer. The hydrothermal synthesis method has associated crack formation troubles, which could be solved by an enhanced adhesion between zeolite layer and substrate. [12, 13].

In the flowing paper, we report the synthesis of an LTA zeolite film on a silicon wafer with $\mathrm{SiO}_{2}$ layer modified with PDDA [10, 12, 14] and Boehmite to facilitate zeolite seed adsorption and to allow the subsequent growth of the LTA zeolite nanocrystals layer without cracks. The effect of the hydrothermal synthesis time during the synthesis of zeolite LTA layer on dioxide silicon support was also investigated.

\section{Design of experiments}

\subsection{Materials}

Aluminum isopropoxide $\left(\mathrm{C}_{9} \mathrm{H}_{21} \mathrm{O}_{3} \mathrm{Al}, 98 \mathrm{wt} \%\right)$, colloidal silica (Ludox AS-30, 30 wt. \% suspension in $\mathrm{H}_{2} \mathrm{O}$ lpH $=$ 9.1)), tetramethylammonium hydroxide pentahydrated (TMAOH. $\left.5 \mathrm{H}_{2} \mathrm{O}, 97 \mathrm{wt} \%\right)$, sodium hydroxide $(\mathrm{NaOH}$, $97 \mathrm{wt} \%$, pellets), hydrogen peroxide $\left(\mathrm{H}_{2} \mathrm{O}_{2}, 35 \mathrm{wt} \%\right)$, cationic polymer, polyldiallyldimethylammonium chloride) $\left(\left(\mathrm{C}_{8} \mathrm{H}_{16} \mathrm{ClN}\right) \mathrm{n} 20 \mathrm{wt} \%\right.$ in water $)$, nitric acid $\left(\mathrm{HNO}_{3}, 64-66\right.$ wt $\%)$ and aluminum tri-sec-butoxide $\left(\mathrm{Al}\left[\mathrm{OCH}\left(\mathrm{CH}_{3}\right) \mathrm{C}_{2} \mathrm{H}_{5}\right]_{3}\right.$, $97 \mathrm{wt} \%$ ) were purchased from Sigma-Aldrich. Sulfuric acid $\left(\mathrm{H}_{2} \mathrm{SO}_{4}, 96 \mathrm{wt} \%\right)$ and sodium chloride $(\mathrm{NaCl}, 99 \mathrm{wt} \%)$ were purchased from Panreac. All the chemical reagents were of analytical grade. Silicon wafers substrates were purchased from SIL'TRONIX Silicon Technologies. The flat substrates used for the preparation of the zeolite-silicon composites were commercial 3-inch silicon wafers with a $<100>$ crystal orientation.

\subsection{Characterization}

The surface microstructure and morphology before and after hydrothermal synthesis, size distribution profile of seeds in suspension and the average seed size deposited onto supports were characterized by Scanning Electron Microscopy (SEM), using an INSPECT FEI Model operated at $5 \mathrm{kV}$. The chemical composition was determined by Energy-disperse X-ray spectroscopy (EDX: INCA Oxford Instruments). The layer thickness was estimated with the same technique by investigating perpendicular fracture surfaces. The average seed size of zeolite was estimated via Dynamic light scattering (DLS: Brookhaven Instrument 90 Plus). The characterization of boehmite was carried out by IR spectroscopy; IVERTEX 70 equipment with a holder MIKI Golden Gate ATR, in the range $4000-600 \mathrm{~cm}^{-1}$ and $a$ band resolution of $5 \mathrm{~cm}^{-1}$ ). The morphology was evaluated by Transmission Electron Microscopy (TEM) using a TECNAI T20 Model, operated at $200 \mathrm{kV}$ and $\mathrm{LaB}_{6}$.

\subsection{Preparation of zeolite LTA seeds}

According to the procedure reported in a previous work by $[6,11]$, LTA nanozeolite seeds were prepared by hydrothermal synthesis. In a typical preparation of 100 $\mathrm{g}$ of zeolite seed, $12.78 \mathrm{~g}$ of LUDOX were diluted in 11.36 $\mathrm{g}$ of DDI water in a polypropylene vessel and was stirred at room temperature until completely dissolved (solution 1). In a separate vessel, $4.26 \mathrm{~g}$ of aluminum isopropoxide, $28.4 \mathrm{~g}$ of tetramethylammonium hydroxide pentahydrate, $39.76 \mathrm{~g}$ of DDI water and $3.4 \mathrm{~g}$ of $1 \mathrm{M}$ sodium hydroxide solution were combined and stirred during 1 hour until completely dissolved (solution 2). Finally, solution 2 was added to solution 1 under stirring during 48 hours at room 
temperature, until homogeneous dissolution, and then the solution was transferred to a polypropylene bottle and heated to $373 \mathrm{~K}$ in rotary evaporator for $15 \mathrm{~h}$ under static conditions.

The zeolite product was subsequently washed with deionized water and dispersed in DDI $\mathrm{H}_{2} \mathrm{O}$, and then it was centrifuged at 10000 r.p.m. for $30 \mathrm{~min}$ and re-dispersed in DDI $\mathrm{H}_{2} \mathrm{O}$ again under ultrasonic bath. The washing procedure was repeated several times obtaining a final dispersion of nanocrystals seeds at $\mathrm{pH}$ 10. The final mixture having a molar composition of $13.4\left(\mathrm{TMA}_{2} \mathrm{O}: 0.3 \mathrm{Na}_{2} \mathrm{O}: 1.8 \mathrm{Al}_{2} \mathrm{O}_{3}: 11.25 \mathrm{SiO}_{2}: 700 \mathrm{H}_{2} \mathrm{O}\right.$ with concentration of $2 \mathrm{wt} \%$. The particle size of seed crystals was $90.8 \mathrm{~nm}$.

\subsection{Preparation and fabrication of zeolite composite substrate}

The deposition of zeolite LTA layer onto the substrate involves two main steps: seeding and hydrothermal growth. The procedure of LTA zeolite layer synthesis is schematically presented in Figure 1. The first step is the seeding process; the surface of silicon oxide support is modified in order to promote the adhesion of colloidal zeolite seeds [13]. The surface of the substrate was modified by two different ways: using a cationic polymer, poly (diallyldimethylammonium chloride) (PDDA) and Boehmite. Zeolite nanocrystals colloidal solution with concentration of $2 \mathrm{wt} \%$ of solid nanocrystals was spread and spanned onto modified support. The seeded support was then hydrothermally treated in the same synthesis solution to allow the growth of zeolite seeds into a dense layer.

These silicon wafers were thermally oxidized at 1273 $\mathrm{K}$ in order to obtain silicon oxidized wafers with a $\mathrm{SiO}_{2}$ thickness of $700 \mathrm{~nm}$. A tubular oven (Carbolite) was used for growing thermal $\mathrm{SiO}_{2}$ layers onto silicon wafers. We carried out two different processes: dry oxidation, using $\mathrm{O}_{2}$ and $\mathrm{N}_{2}$, and wet oxidation, bubbling $\mathrm{O}_{2}$ and $\mathrm{N}_{2}$ through DDI water. The usual procedure for making a mixed oxide sandwich grow is dry oxidation + wet oxidation + dry oxidation. The water required for the wet oxidation is obtained by saturating the input stream of oxygen through a bubbler to $373 \mathrm{~K}$. The process variables are oxidant gas composition and the oven temperature. Before the seeding process, silicon oxide substrates were first sonicated in acetone for $10 \mathrm{~min}$, then in a mixture of acetone $(50 \%)$ and ethanol (50\%) for others $10 \mathrm{~min}$, and later rinsed with a copious amount of deionized water. After that, silicon oxide wafers were cleaned in freshly prepared Piranha solution (a mixture of $30 \% \mathrm{H}_{2} \mathrm{O}_{2}$ and $70 \%$ of $\mathrm{H}_{2} \mathrm{SO}_{4}$ ) for at least $0.5 \mathrm{~h}$, rinsed exhaustively with deionized water, and dried in a stream of nitrogen gas.
The PDDA solution was prepared by solving $1.47 \mathrm{~g}$ of $\mathrm{NaCl}$ and $0.25 \mathrm{~g}$ of PDDA in $50 \mathrm{ml}$ of DDI water, the solution was stirred until the poly (diallyldimethylamonium chloride) was completely dissolved, and then the solution was spanned onto the silicon substrate. Finally, the silicon substrate was seeded with zeolite nanocrystals before hydrothermal synthesis. The initial angular speed was 170 r.p.m for 1.5 minutes, for spreading all the de-posited material onto the substrate. Then the substrate was spanned at 4000 r.p.m for 2 minutes, in order to finish the covering and evaporate the solvent. These parameters reproduce the optimal conditions reported by previous work [15].

Boehmite nanoparticles were prepared by a peptization method. According to Yoldas' procedure (1975) [16], $25 \mathrm{~g}$ of aluminum tri-sec-butoxide precursor was hydrolyzed in $100 \mathrm{~mL}$ of distilled water at $353 \mathrm{~K}$ for $1 \mathrm{~h}$, under vigorous stirring to form a white precipitate. Then $7 \mathrm{~mL}$ of nitric acid was added and the temperature raised to $363 \mathrm{~K}$ for $20 \mathrm{~h}$. At the end of this process, a sol containing 9 wt $\%$ of boehmite $\mathrm{AlO}(\mathrm{OH})$ was obtained. The boehmite layer was applied by spin coating method. Initially the boehmite solution was spinned onto silicon dioxide wafer. Spinning was applied during 1 minute at 100 r.p.m followed by 0.5 minute at $3000 \mathrm{rpm}$. It was repeated 8 times. Then, the substrate was dried at $473 \mathrm{~K}$ for $2 \mathrm{~h}$. A thin layer of boehmite was formed on the support surface. The support substrate modified with boehmite was spinned with a 2 wt\% LTA-type zeolite suspension in deionized water 5 times for 1 minute at 100 r.p.m in order to thin the fluid and then 0.5 minute at 3000 r.p.m to eliminate excess of solvents from the resulting film. After the spinning procedure, the seeded supports were dried at $423 \mathrm{~K}$ for 24 h. The LTA zeolite layer was hydrothermally synthesized on modified silicon dioxide seeded support wafer.

\subsection{Hydrothermal synthesis of LTA-type zeolite layer}

LTA-type zeolite layer onto silicon dioxide wafer was synthesized according to the procedure described in a previous work [17] as follows: A gel having $2.8 \mathrm{Na}_{2} 0: 2.7 \mathrm{SiO}_{2}: 1 \mathrm{Al}_{2} \mathrm{O}_{3}: 174-347 \mathrm{H}_{2} 0: 0.05\left(\mathrm{TMAl}_{2}\right.$ molar composition was prepared using LUDOX AS-30 as silica source and sodium aluminate $\left(\mathrm{AlO}_{2} \mathrm{Na}\right.$ Quimivita) as Al source. A typical preparation involved a mixture of $0.9 \mathrm{~g} \mathrm{NaOH}, 0.27 \mathrm{~g}$ of tetramethylammonium hydroxide (TMAOH) and $2.78 \mathrm{~g}$ of sodium aluminate in $40 \mathrm{~g}$ of DDI water with continuous stirring. At the same time, $8.10 \mathrm{~g}$ of LUDOX AS-30 were mixed with $47.9 \mathrm{~g}$ of water and then stirred. After aging separately for $1 \mathrm{~h}$, both solutions were mixed slowly under stirring at room temperature. The resulting mixture was stirred vigorously for 18 hours to produce a homogeneous gel. Then, the seeded wafer 


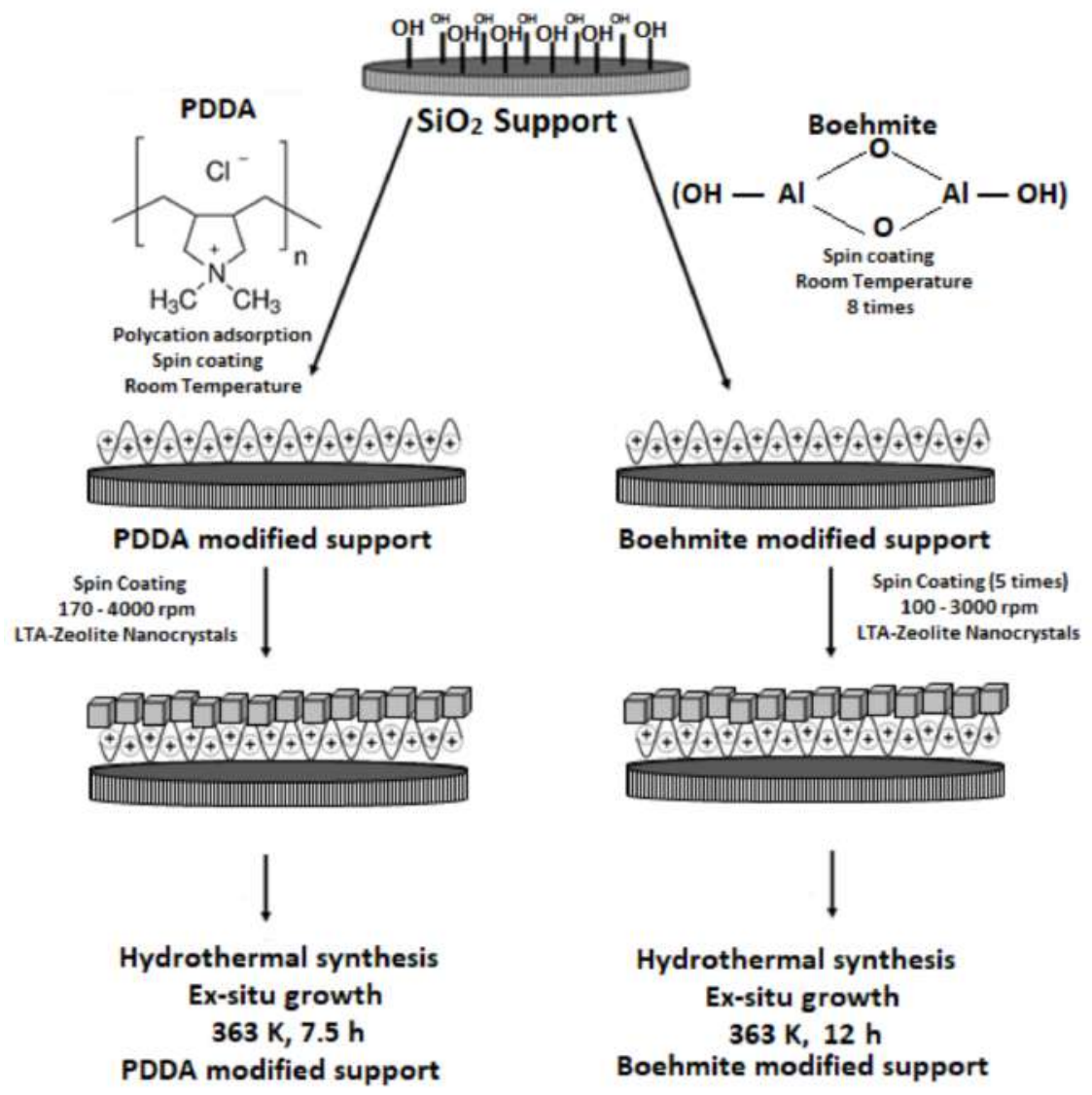

Figure 1 Scheme of the hydrothermal synthesis of a zeolite layer using poly (diallyldimethylammonium chloride) or Boehmite as interlayer. In the first step, the support was modified by PDDA and Boehmite, following seeding steps and finally, hydrothermal synthesis Source: The authors

was placed in horizontal position with the seeded surface facing downwards into the synthesis solution and during hydrothermal synthesis in a Teflon-lined autoclave at 363 $\mathrm{K}$ for $7.5 \mathrm{~h}$ under static conditions for modified support with PDDA and $12 \mathrm{~h}$ for modified support with Boehmite. A Teflon-lined stainless-steel autoclave with a reactor volume of $850 \mathrm{~cm}^{3}$ was used in the zeolite crystallization and growth. The resulting LTA-type zeolite layers were washed with deionized water and dried at $423 \mathrm{~K}$ in air for 24 hours.

\section{Result and discussion}

\subsection{Synthesis of LTA-zeolite seeds}

In Figure 2a, a SEM micrograph of the zeolite LTA nanocrystals used as seeds is shown. Results from the SEM image fit with the results obtained from DLS (Figure $2 \mathrm{a}$ and $2 \mathrm{~b}$ ). Two different populations are observed with DLS technique for the $48 \mathrm{~h}$ of aging and $15 \mathrm{~h}$ of seeds synthesis time, one population is located around \pm 108.4 $\mathrm{nm}$ and the other about $\pm 17.1 \mathrm{~nm}$. The average crystal size reported by DLS was $90.8 \mathrm{~nm}$ and the polydispersity index was 0.16 . In case the value of the polydispersity index is significantly higher than 0.2 , the calculated hydrodynamic radius is no longer reliable. The seeds have a typical cubic form from the LTA zeolite.

Elemental analysis was carrie on over cross section of zeolite film. EDX-SEM results show that the synthesized product only contained Silicon, Aluminum, Sodium and Oxygen atoms. Si/Al ratio in synthesized zeolite seed and crystal layer were 1.57 and 1.19, respectively. These values were according with the reported range of LTA-zeolite compositions [1, 2]. These results indicate that after calcination, the Si/Al ratio of zeolite crystals is lower than zeolite seeds, because the aluminum concentration increases at zeolite film, due to the possible aluminum migration from the boehmite layer to the zeolite film during calcination [17]. Table 1 shows the comparison between composition of zeoite seed synthesized without support and cross-section composition of zeolite crystal layer prepared in this work with boehmite. Both samples were calcinated at $480^{\circ} \mathrm{C}$ by 8 hours with a thermal rate ramp of $1^{\circ} \mathrm{C} / \mathrm{min}$. In the case of zeolite seeds, using of 
a
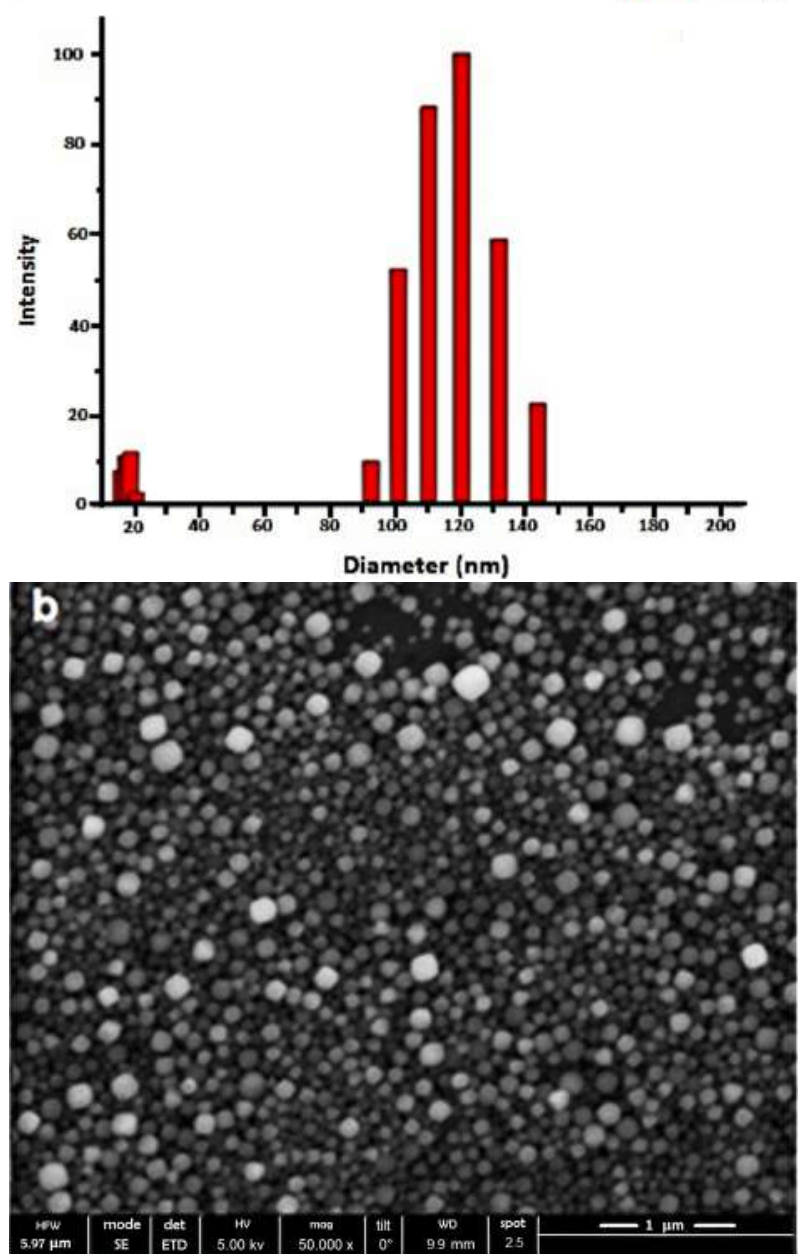

Figure 2 al Size and polydispersity of the sample using DLS, from obtained 13.4(TMA) $20: 0.3 \mathrm{Na}_{2} \mathrm{O}: 1.8 \mathrm{Al}_{2} \mathrm{O}_{3}: 11.25 \mathrm{SiO}_{2}: 700 \mathrm{H}_{2} \mathrm{O}$ for $373 \mathrm{~K}$ and $15 \mathrm{~h}$. Mean Diam 108,4 nm and Mean Diam $17.1 \mathrm{~nm}$ b) SEM micrographs of LTA- zeolite seed Source: The authors

template in the synthesis of zeolites tends to change the $\mathrm{Si} / \mathrm{Al}$ ratio of the final products. For example, LTA zeolite, synthesized by using template (tetramethylammonium), has a Si/Al ratio about 2 . In contrast, template-free synthesis leads to $\mathrm{Si} / \mathrm{Al}=1[1,2]$. As a result of the increase of Si/Al ratio, thermal and chemical stability of the product will be remarkably improved.

\subsection{Hydrothermal synthesis of A-type zeolite polycrystalline coatings by secondary growth}

The PDDA and Boehmite linkers adsorbed on the support surface were used to capture LTA zeolite particles during hydrothermal synthesis. The use of PDDA allows reversing the charge of the $\mathrm{SiO}_{2}$ surface, in order to obtain a positively charged substrate and produce attractive electrostatic interactions between the surface of the substrate and the zeolite nanocrystals, PDDA is always cationic, regardless of $\mathrm{pH}$ [18]. However, Boehmite showed better results than the PDDA because it also generates a layer that will protect the wafer from the basic medium present in the dissolution of the synthesis gel, the boehmite intermediate layer enhance the adherence between zeolite seed layer and substrate by hydrogen bonding. PDDA and bohemite modify the surface charge of the support from negative to positive favoring the deposition of negatively charged crystals [19].

Figure 3 shows a comparison between zeolite LTA nanocrystals by SEM micrographs after the seeding procedure using PDDA (Figure 3a) and Boehmite (Figure $3 \mathrm{~b})$ as linker. A greater and uniform seed coverage was obtained with boehmite linker; approximately $80 \%$ of the silicon surface is covered by a monolayer of seed crystals. As 9 wt \% boehmite layers with LTA seed crystals on the support surface were found to be a relatively compact layer with better surface coverage, they were chosen for film formation of LTA zeolite through secondary crystallization.

Additionally, the main problem associated with hydrothermal synthesis is crack formation $[12,13,17]$. In previous works, PDDA has been used as a covalent linker between zeolite seed and silicon support; however, forming cracks in the zeolitic coatings cannot be avoided [15]. One of the causes of cracks of zeolite LTA layer was the lack of good adherence and the mismatch of thermal expansion between zeolite layer and silicon substrate. This phenomenon is improved, but not completely eliminated, with the use of boehmite as linker between zeolite seed and silicon support.

The boehmite crystals structure consists of double chain of $\mathrm{AlO}_{6}$ octahedral giving double molecules. These chains are parallel, forming layers with $\mathrm{OH}$ group outside. These hydroxyl groups will form hydrogen bonds between the hydroxyl ion and the neighboring group. Hydroxyl group of boehmite layer acts as binder between zeolite and support layer [17].

A TEM micrograph (Figure 4a) of the boehmite sample indicates that the nanoparticles were spherical in shape and tended to form aggregated clusters with an apparent "particle" size in a range similar to the one determined by the light-scattering method. The "real" particle size of boehmite might be less than $10 \mathrm{~nm}$ [20]. The result obtained from DLS indicated a polydispersity with an average size of $\sim 1.4 \mu \mathrm{m}$ (Figure $3 \mathrm{~b}$ ).

Figure 5 shows the IR spectra of a 9 wt\% boehmite sample before calcination at $600{ }^{\circ} \mathrm{C}$. Typical bands for crystallized boehmite [21] can be observed: $3000-3600$ 
Table 1 Comparison between the chemical composition of the synthesized zeolite crystal of LTA and the zeolite film deposited on silicon substrate by Energy-Dispersive X-ray Spectroscopy (EDXS)

\begin{tabular}{lll|lll}
\hline & Zeolite Seed & \multicolumn{3}{c}{ Zeolite crystal layer } \\
Element & Weight \% & Atomic \% & Element & Weight \% & Atomic \% \\
\hline Oxygen & 49.80 & 62.26 & Oxygen & 44.43 & 55.31 \\
Sodium & 9.65 & 8.40 & Sodium & 31.58 & 27.36 \\
Aluminum & 15.95 & 11.83 & Aluminum & 10.93 & 8.07 \\
Silicon & 24.59 & 17.51 & Silicon & 13.05 & 9.26 \\
Si/Al & $\mathbf{1 . 5 4}$ & - & Si/Al & $\mathbf{1 . 1 9}$ & - \\
Total & 100 & 100 & Total & 100 & 100 \\
\hline
\end{tabular}

Source: The authors

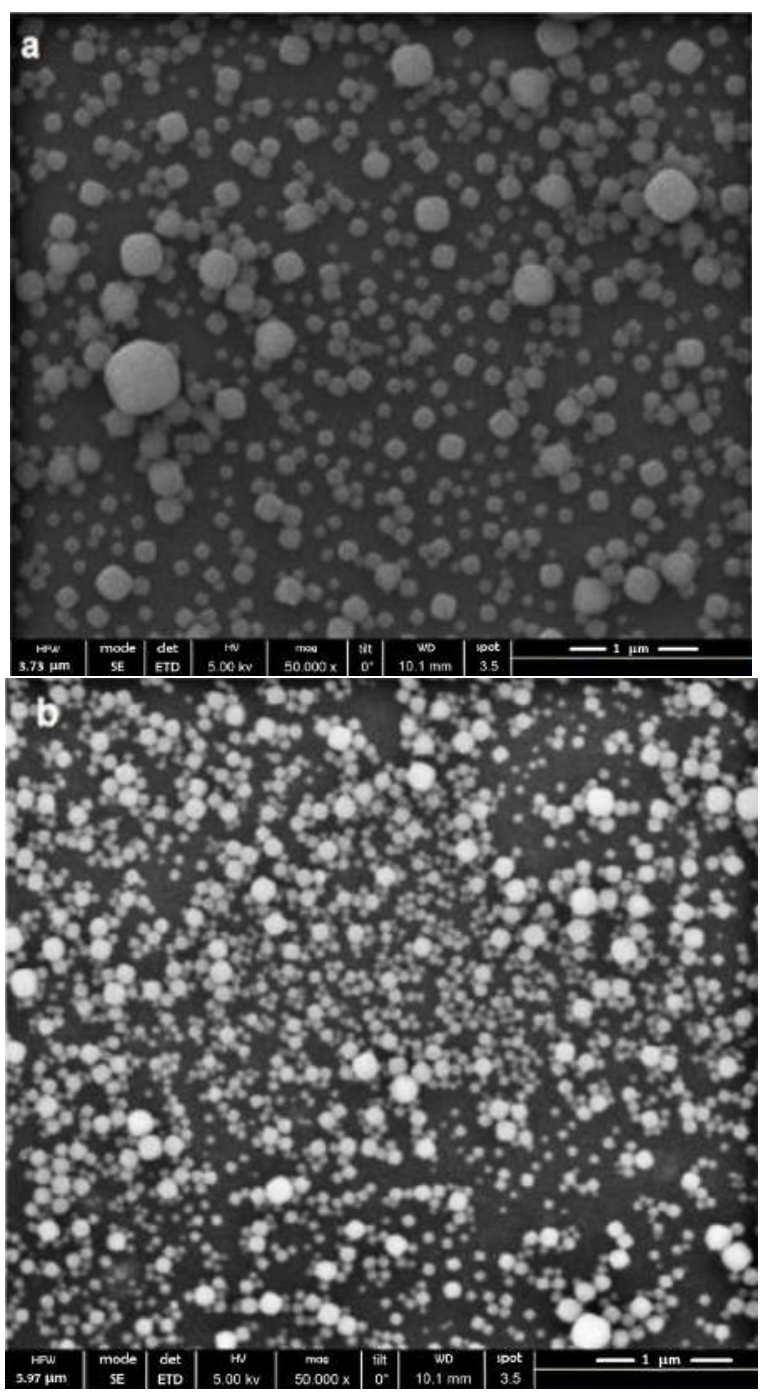

Figure 3 Zeolite seed coating using a) PDDA b) Boehmite, as an interlayer Source: The authors

$\mathrm{cm}^{-1}, 0-\mathrm{H}$ stretching vibrations; $1150 \mathrm{~cm}^{1}, 0-\mathrm{H}$ bending vibrations; $1637 \mathrm{~cm}^{-1}, 1355 \mathrm{~cm}^{-1}$, and $1078 \mathrm{~cm}^{-1}$ which can be assigned to $\mathrm{Al}=\mathrm{O}, \mathrm{Al}-\mathrm{OH}$, and $\mathrm{Al}-\mathrm{O}-\mathrm{Al}$ bonds, respectively. The vibrations that appear in the 3000-3600

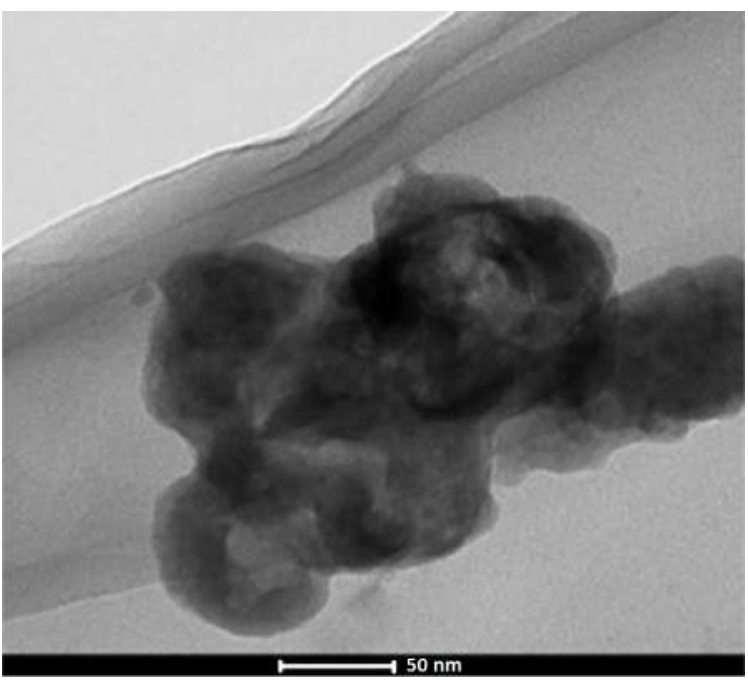

(a)

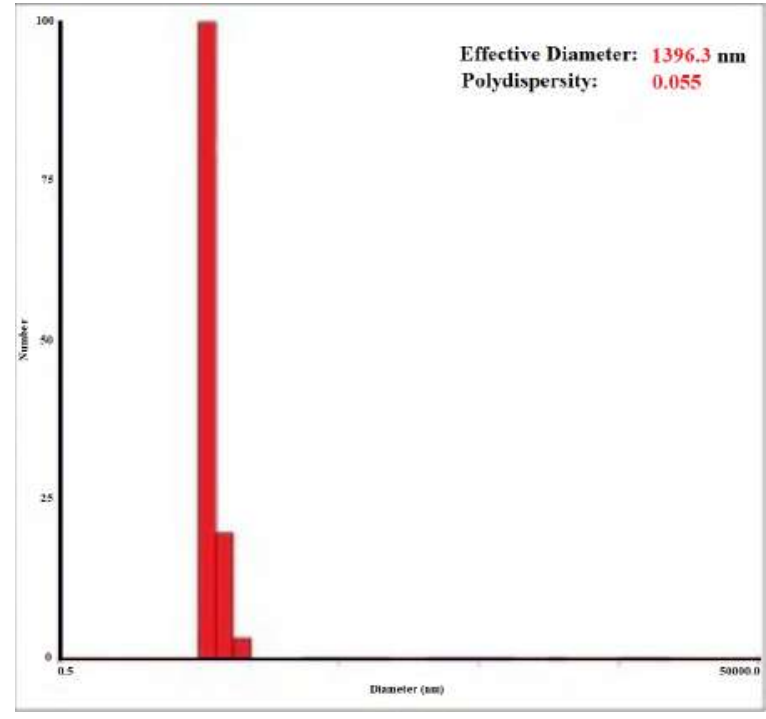

(b)

Figure $\mathbf{4}$ a) TEM image of boehmite nanoparticles synthesized from the $\mathrm{Al}\left(\mathrm{OCH}\left(\mathrm{CH}_{3}\right)_{2}\right)_{3}$ precursor in acid at $363 \mathrm{~K}$. b) DLS of Boehmite. Mean Diam. 1.4 $\mu \mathrm{m}$ Source: The authors 


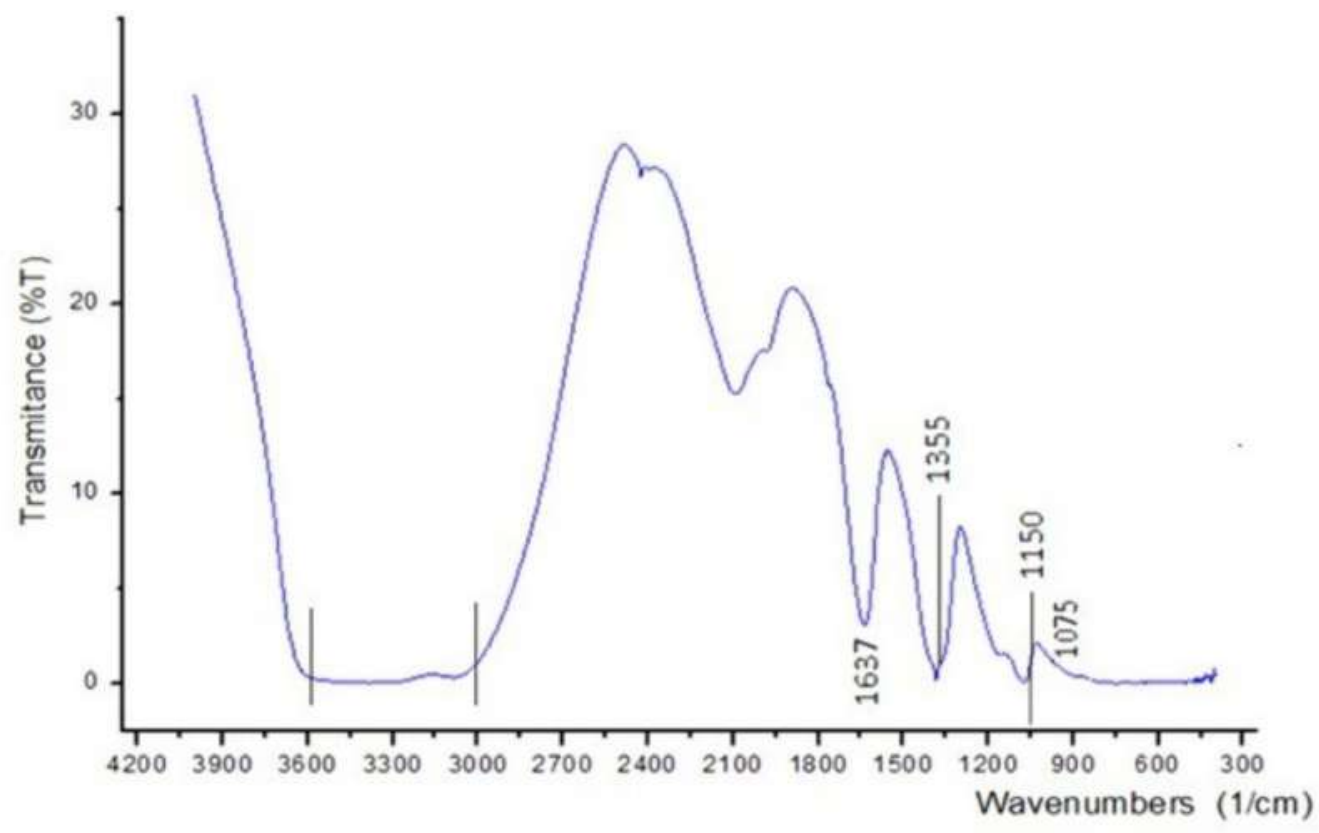

Figure 5 IR spectra of Boehmite measured in the range $4000-600 \mathrm{~cm}^{-1}$ and a band resolution of $5 \mathrm{~cm}^{-1}$ Source: Authors
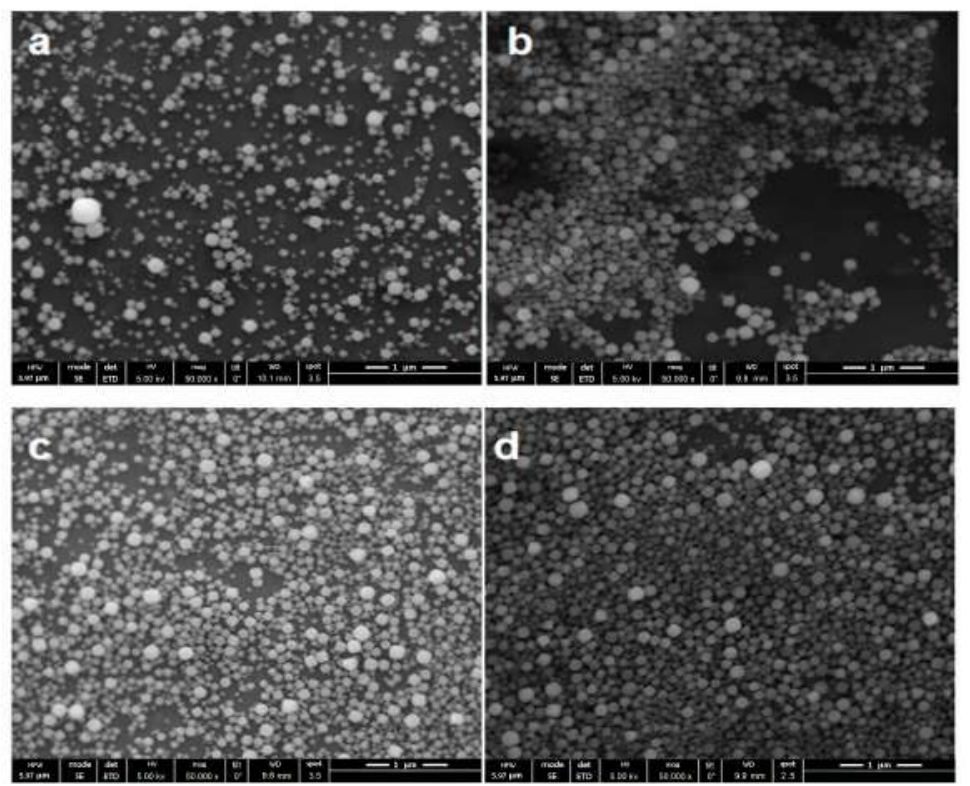

Figure 6 Multistage coating method: Boehmite solution ( 9 wt \%) was spinned a) Once b) 3 times c) 5 times d) 8 times. Zeolite seed solution ( 1 wt \%) was spinned 5 times onto silicon dioxide wafers Source: The authors

$\mathrm{cm}^{-1}$ range as strong peaks are characteristic for $-\mathrm{OH}$ fragments of physisorbed water.

The coating coverage quality of zeolite seeds can be improved by a multistage coating method. Boehmite solution ( $9 \mathrm{wt} \%$ ) was spinned one, three, five and eight times onto four different silicon dioxide wafers; Figure 6 shows SEM images of results with this method. The coating coverage increase with the times that the boehmite was spinned onto the support. The boehmite solution was spinned repeatedly on the silicon wafer in order to enhance adherence and zeolite seed coating. In all cases the zeolite seed solution ( $2 \mathrm{wt} \%$ ) was spinned five times onto boehmite layer. Figure $6 \mathrm{~d}$, boehmite solution was spinned 8 times, shows better coverage of zeolite seed coating. Higher values did not show significant differences in the quality of coating. 


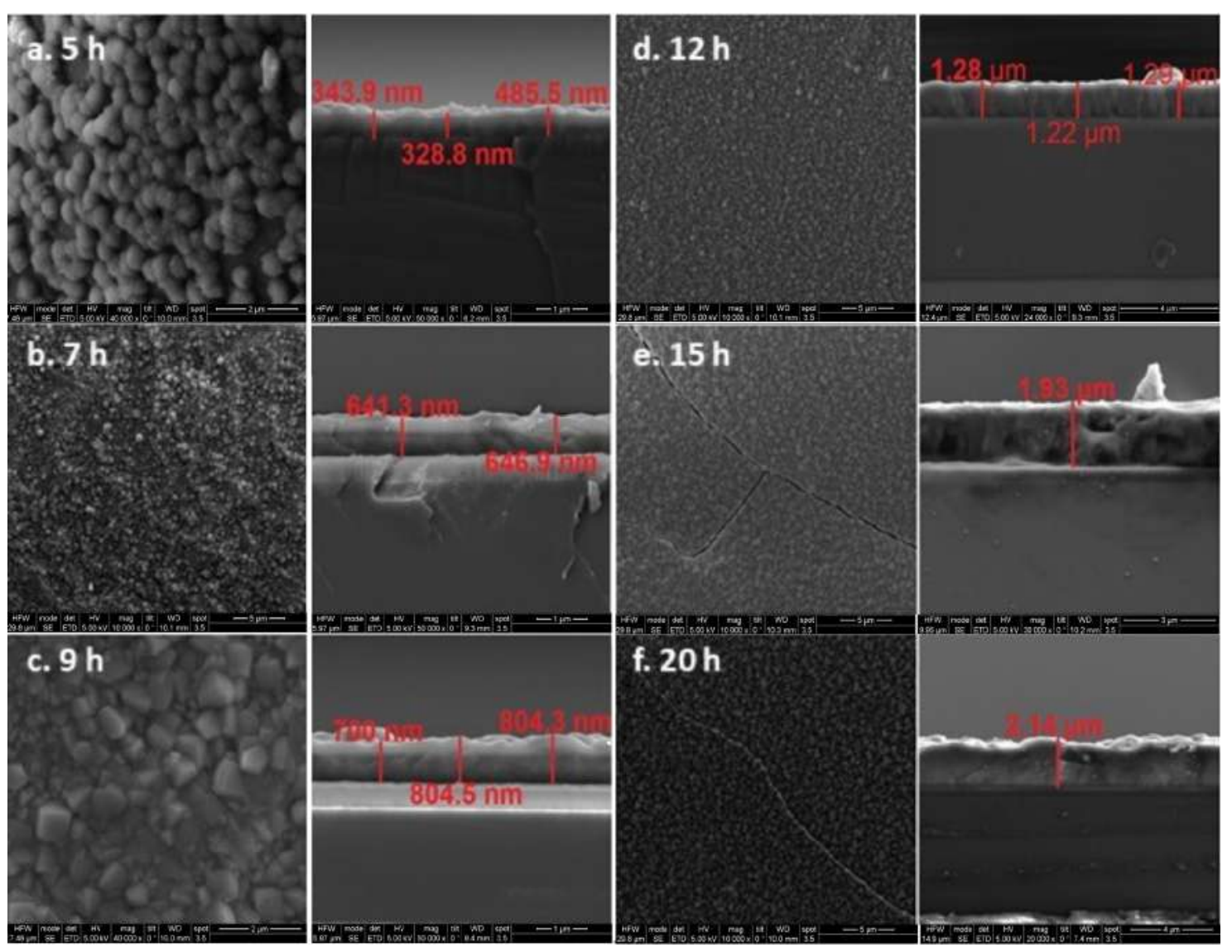

Figure 7 Micrographs (Top view and cross-section) wafer to different hydrothermal synthesis time. a) 5 h ( $350 \mathrm{~nm}$ ), b) $7 \mathrm{~h}$ ( $\sim 650$ $\mathrm{nm})$, c) $9 \mathrm{~h}(\sim 750 \mathrm{~nm})$, d) $12 \mathrm{~h}(\sim 1.5 \mu \mathrm{m})$, e) $15 \mathrm{~h}(\sim 1.93 \mu \mathrm{m})$, f) $20 \mathrm{~h}(\sim 2.14 \mu \mathrm{m})$ Source: The authors

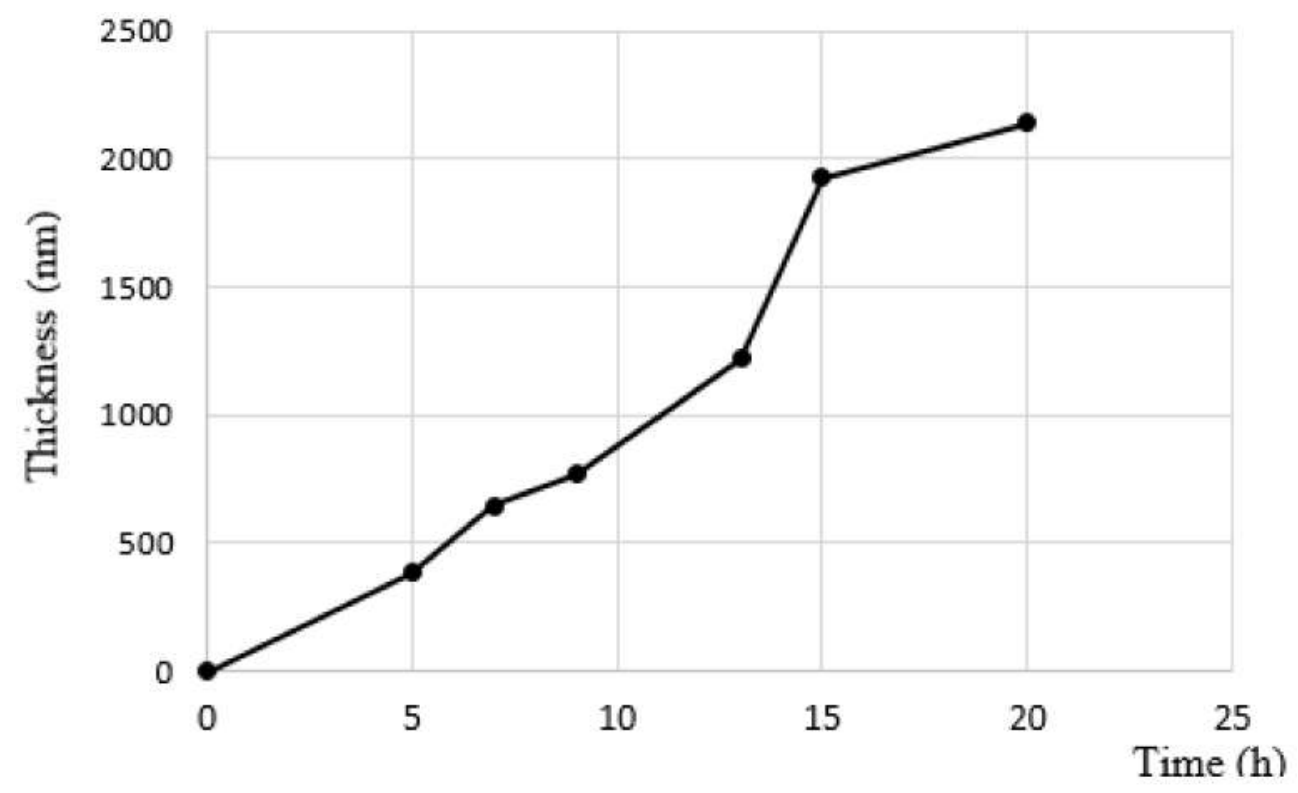

Figure 8 Graphical thickness layer as a function of synthesis time

The next step in the fabrication of zeolite-silicon composite substrate was hydrothermal synthesis. Six pieces of silicon dioxide wafer were modified with boehmite solution and zeolite nanocrystals seeds solution in order to evaluate synthesis time to five, seven, nine, twelve, fifteen and twenty hours. In all samples, a uniform and homogeneous 
zeolite seed coating was obtained. The zeolite-silicon composite after the synthesis was rinsed with deionized water and dried in a heating plate at $423 \mathrm{~K}$ for $24 \mathrm{~h}$. The Figure 7 illustrates the result.

SEM was used to examine the zeolite layers' synthetized quality. The micrographs reveal that increasing the synthesis time increments the layer thickness. Figure 8 illustrates the increase in layer thickness as function of time; a maximum thickness of 2.14 micrometers was obtained before $20 \mathrm{~h}$ of synthesis (Figure 7f). However, in the highest synthesis times (15 and $20 \mathrm{~h}$ ), the crystal layer shows cracks formation (Figure 7e). It could be caused by mismatch of thermal expansion coefficient between zeolite layer and silicon support. Otherwise, 12 hours (Figure $7 \mathrm{~d}$ ) of synthesis time allows $1.30 \mathrm{~m}$ of thick growing without (Figure $7 \mathrm{a}-\mathrm{c}$ ) crack formation.

\section{Conclusions}

A preparation of continuous thin LTA zeolite crystal layer on $\mathrm{Si}+\mathrm{SiO}_{2}$ supports has been presented in this work. The crystal layer was prepared by modification of silicon support with cationic polymer PDDA and boehmite mineral, in order to determine which one helps improve the deposition of zeolite seeds, followed by an ex situ hydrothermal synthesis. A substantial improvement, in terms of LTA zeolite seed coverage, was observed when comparing coatings prepared on boehmite modified supports and on PDDA modified supports. Conditions were established for the coatings of LTA zeolite seeds and intergrowth of film/coatings on silicon supports. The thickness of the films was linearly dependent on the synthesis duration. A maximum in the LTA film thickness was observed after prolonged hydrothermal treatment of 20 hours, but we observed formation of cracks. Zeolite films with low Si/Al ratio were prepared on silicon supports according to a procedure previously developed by our research group at $363 \mathrm{~K}$ by 12 hours. The methods of synthesis of Zeolite LTA have been improved, due to the incorporation of a layer of boehmite that allows the thickness of $\pm 1.3 \mu \mathrm{m}$ and that favor the absence of cracks. The improved zeolite layer fabrication procedure may form the basis to scale up synthesis to $3 D$ substrate.

\section{Declaration of competing interest}

We declare that we have no significant competing interests including financial or non-financial, professional, or personal interests interfering with the full and objective presentation of the work described in this manuscript.

\section{Acknowledgement}

This work was supported by Carolina Fundation, University of Zaragoza and Institute of Nanoscience of Aragon (INA).

\section{References}

[1] J. G. García, "Synthesis and applications of low silica zeolites from bolivian clay and diatomaceous earth," Ph.D. Dissertation, Luleå University of Technology, Luleå, Sweden, 2017.

[2] P. Singh, V. K. Aswal, S. G. Chaudhri, and W. Schwieger, "Structural evolution during nucleation of Si-rich LTA nanocrystals from colloidal solution," Microporous and Mesoporous Materials, vol. 259, March 15 2018. [Online]. Available: https://doi.org/10.1016/j. micromeso.2017.10.006

[3] S. M. Auerbach, K. A. Carrado, and P. K. Dutta, Handbook of zeolite science and technology. Boca Raton, FL, USA: CRC Press, 2003.

[4] 0. Y. Dudchenko and et al., "Development of silicalite/glucose oxidase-based biosensor and its application for glucose determination in juices and nectars," Nanoscale Research Letters, vol. 11, February 03 2016. [Online]. Available: https: //doi.org/10.1186/s11671-016-1275-2

[5] T. D. Caliskan, D. A. Bruce, and M. F. Daqaq, "Micro-cantilever sensors for monitoring carbon monoxide concentration in fuel cells," Journal of Micromechanics and Microengineering, vol. 30, no. 4, pp. 1-9, Feb. 2020.

[6] G. P. Alcantara, L. E. B. Ribeiro, A. F. Alves, C. M. G. Andrade, and F. Fruett, "Humidity sensor based on zeolite for application under environmental conditions," Microporous and Mesoporous Materials, vol. 247, July 15 2017. [Online]. Available: https: //doi.org/10.1016/j.micromeso.2017.03.042

[7] C. S. Cundy and P. A. Cox, "The hydrothermal synthesis of zeolites: Precursors, intermediates and reaction mechanism," Microporous and Mesoporous Materials, vol. 82, no. 1-2, July 05 2005. [Online]. Available: https://doi.org/10.1016/j.micromeso.2005.02.016

[8] K. Xu and et al., "Seeding-free synthesis of oriented zeolite LTA membrane on pdi-modified support for dehydration of alcohols," Separation Science and Technology, vol. 53, no. 11, February 122018. [Online]. Available: https://doi.org/10.1080/01496395.2018.1434203

[9] J. Gao, T. Mitsumata, N. Tsubokawa, and T. Yamauchi, "Synthesis of chitosan-NaA membranes with non-uniform seeds on defective supports," Microporous and Mesoporous Materials, vol. 299, June 2020. [Online]. Available: https://doi.org/10.1016/j.micromeso.2019. 109648

[10] L. Orobitg, "Development of zeolite-silicon composites to be used as substrates in microfabrications applications," M.S. thesis, Universidad de Zaragoza, Zaragoza, España, 2011.

[11] B. Yoldas, "Alumina sol preparation from alkoxides," American Ceramic Society Bulletin, vol. 54, pp. 289-290, 1975.

[12] I. Pellejero, "Fabricación de microdispositivos basados en zeolitas y su aplicación en sensores y membranas," Ph.D. Dissertation, Universidad de Zaragoza, zaragoza, spain, 2012.

[13] M. Tatlier, L. Rustam, and G. Munz, "Tailoring the reaction mixture composition for preparing zeolite coatings on aluminum supports in alkaline environments," Chemical Engineering Communications, vol. 206, no. 7, November 14 2018. [Online]. Available: https: //doi.org/10.1080/00986445.2018.1539711

[14] A. Huang and J. Caro, "Cationic polymer used to capture zeolite precursor particles for the facile synthesis of oriented zeolite LTA molecular sieve membrane," Chemistry of Materials, vol. 22, no. 15, July 16 2010. [Online]. Available: https://doi.org/10.1021/ cm1016189

[15] M. Jafari, T. Mohammadi, and M. Kazemimoghadam, "Synthesis and characterization of ultrafine sub-micron Na-LTA zeolite particles prepared via hydrothermal template-free method," Ceramics International, vol. 40, no. 8, September 2014. [Online]. Available: https://doi.org/10.1016/j.ceramint.2014.04.047 
[16] F. Karouia, M. Boualleg, M. Digne, and P. Alphonse, "The impact of nanocrystallite size and shape on phase transformation: Application to the boehmite/alumina transformation," Advanced Powder Technology, vol. 27, no. 4, July 2016. [Online]. Available: https://doi.org/10.1016/j.apt.2016.06.014

[17] J. Karger and L. Lendvai, "Polymer/boehmite nanocomposites: A review," Journal of Applied Polymer Science, vol. 135, no. 24, June 20 2018. [Online]. Available: https://doi.org/10.1002/app.45573

[18] T. Ratajski and et al., "Effect of PDDA surfactant on the microstructure and properties of electrodeposited $\mathrm{SiO}_{2} / \mathrm{Ni}$ nanocomposites," Materials Characterization, vol. 163, May 2020. [Online]. Available: https://doi.org/10.1016/j.matchar.2020.110229
[19] M. U. Anu, B. Kaur, and R. Srivastava, "Electrochemical sensor platforms based on nanostructured metal oxides, and zeolitelbased materials," The Chemical Record, vol. 19, no. 5, May 2019. [Online]. Available: https://doi.org/10.1002/tcr.201800068

[20] N. Kosinov, J. Gascon, F. Kapteijn, and E. J. M. Hensen, "Recent developments in zeolite membranes for gas separation," Journal of Membrane Science, vol. 499, February 1 2016. [Online]. Available: https://doi.org/10.1016/j.memsci.2015.10.049

[21] S. Fasolin and et al., "Single-step process to produce alumina supported hydroxy-sodalite zeolite membranes," J. Mater. Sci., vol. 54, no. 1, February 2019. [Online]. Available: https://doi.org/10. 1007/s10853-018-2952-6 